\title{
NOTE
}

\section{Cardiac abnormality with associated hernia in farmed rainbow trout Oncorhynchus mykiss}

\author{
Trygve T. Poppe ${ }^{1, *}$, Renate Johansen ${ }^{2}$, Brit Tørud ${ }^{3}$ \\ ${ }^{1}$ Norwegian School of Veterinary Science, Institute of Morphology, Genetics and Aquatic Biology, PO Box 8146 Dep., 0033 Oslo, Norway \\ ${ }^{2}$ National Veterinary Institute, Section of Fish Health, PO Box 8156 Dep., 0033 Oslo, Norway \\ ${ }^{3}$ Veterinary Service in Aquaculture (VHHAS), 6681 Valsøyfjord, Norway
}

\begin{abstract}
A new type of cardiac malformation in rainbow trout Oncorhynchus mykiss from a broodstock fish farm is described. The ventricle of affected fish was located dorsodextrally to the atrium, while the latter was saccular, grossly enlarged and protruded through the muscles of the ventral body wall, forming a hernia covered only by dermis and epidermis. Histopathological changes included hypoplasia of the outer compact layer of the ventricular myocardium and severe distension of trabecular structures within the ventricle and atrium. Affected fish tolerated stress very poorly, and the majority of the affected fish died during the freshwater period. The causation(s) are not known, but hereditary and environmental factors are likely, as no infectious agents were isolated or detected microscopically.
\end{abstract}

KEY WORDS: Oncorhynchus mykiss · Cardiac malformation · Hernia

Resale or republication not permitted without written consent of the publisher

Numerous cardiac malformations have been observed in farmed Atlantic salmon Salmo salar and rainbow trout Oncorhynchus mykiss in recent years. These include situs inversus of the heart and aplasia of the septum transversum (Kaada \& Hopp 1995, Bruno \& Poppe 1996, Poppe et al. 1998), hypoplasia of the outer compact layer of the ventricle (Poppe \& Taksdal 2000), fibro-haemangioma of the ventricle (Poppe \& Taksdal 1997) and aberrant ventricle morphology (Johansen \& Poppe unpubl. data). This note deals with a new type of cardiac malformation in farmed rainbow trout.

Materials, methods and results. During routine examination of rainbow trout at a breeding station, several fish with a prominent distension of the cranial abdominal wall were observed. It was reported by the fish farmer that such fish had been observed frequently and were dominating the daily mortality. The number of fish affected cannot be ascertained as these were removed routinely together with cases of normal

*E-mail: trygve.poppe@veths.no mortality without being recorded separately. The weight of the fish in the population varied between 15 and $25 \mathrm{~g}$. Necropsy revealed fish in normal condition with the exception of a conspicuous, dark, 10 to $12 \mathrm{~mm}$ long distension in the midline of the abdominal wall between the pectoral fins. An underlying organ seemed to protrude through the muscular layers, while the dermis and epidermis remained intact with melanocytes showing clearly (Fig. 1). Careful dissection revealed that the atrium of the heart had lost its normal lobular shape and appeared grossly enlarged, rounded and saccular. The ventricle was smaller than normal, appeared compressed, and was located dorsodextrally to the atrium, i.e. in contrast to the normal cardiac arrangement in salmonids (Ferguson 1989, Agnisola \& Tota 1994) (Fig. 2). The organ mass protruding through the ventral wall was found to be the enlarged, saccular atrium. Besides congestion, there were no gross visible lesions in other organs. The entire thoracic region of each of 6 fish was fixed in saline-buffered formalin and 2 of these hearts were subsequently carefully dissected free and prepared separately. No bacteria were isolated from affected fish.

Histology of the entire pericardial cavity with adjacent tissues and the free-dissected heart revealed severe congestion and enlargement of the atrium and sinus venosus (Fig. 4). The atrial wall was thin and distended, with few myocardial trabeculae, and blood clots filled the entire lumen, reflecting the gross findings. The ventricle with bulbus arteriosus was located dorsodextrally to the atrium and was smaller than normal and dorsoventrally flattened (Fig. 3a). The outer compact muscle layer was hypoplastic, leaving the ventricle wall almost identical to the atrial wall (Fig. 3b). Furthermore, the inner spongious myocardium was extensively stretched, with a well-defined lumen far more conspicuous than in normal ventricles. 

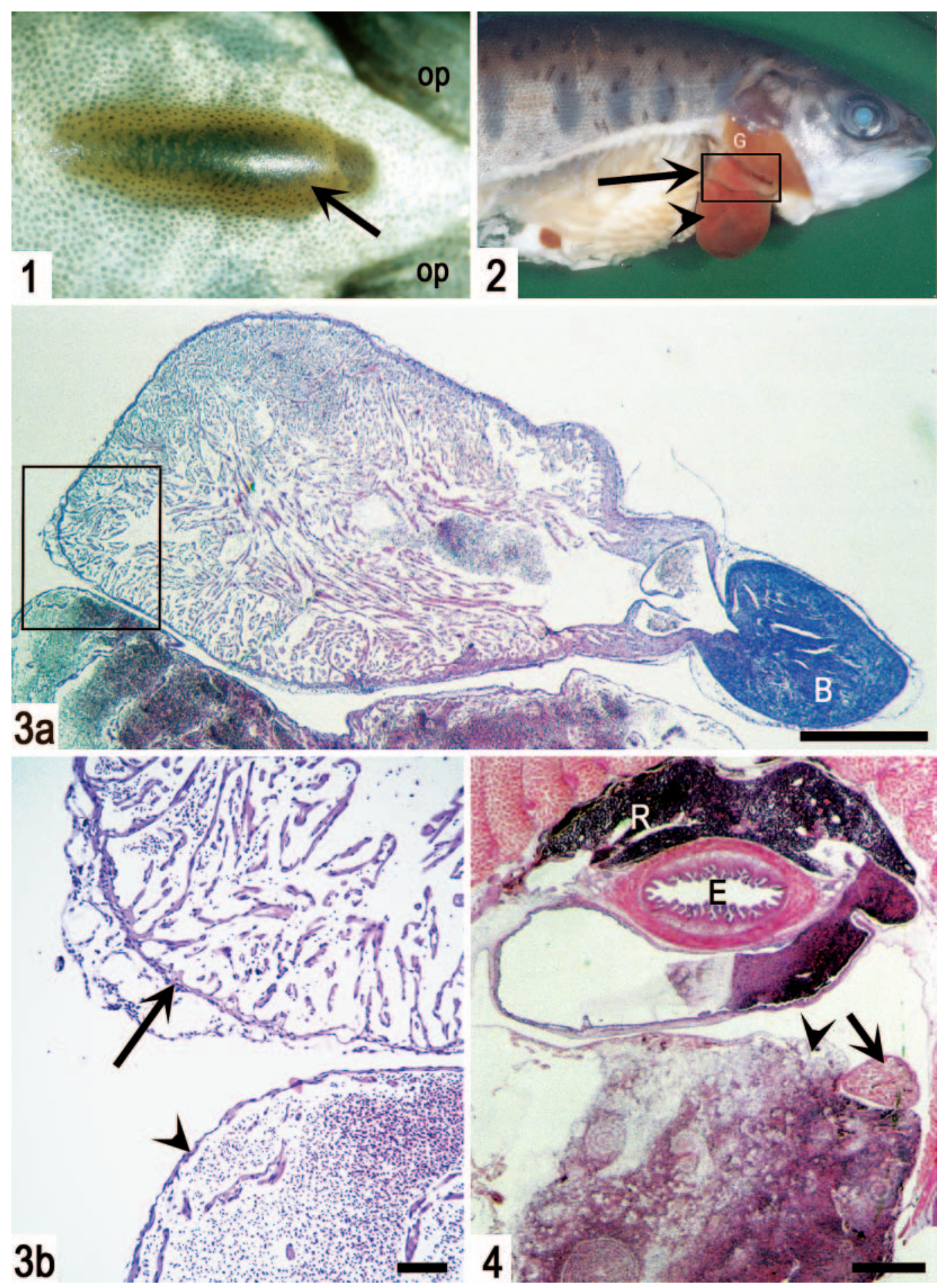

Figs. 1 to 4. Oncorhynchus mykiss. (All figures except Fig. 4 are from the same formalin-fixed rainbow trout and aligned with the head towards the right.) Fig. 1. Ventral view of the epidermis-covered hernia (arrow) located between the pectoral fins (op: operculum). Fig. 2. Right lateral view, with the heart and peritoneal cavity exposed; the ventricle (arrow) is located dorsodextrally to the enlarged, saccular atrium (arrowhead); framed part is shown in Fig. 3a (G: gill). Fig. 3a. Low-power magnification of the abnormally shaped free-dissected heart (B: bulbus arteriosus; H\&E; scale bar $=1 \mathrm{~mm}$ ). Fig. 3b. Higher magnification of frame shown in Fig. 3a; the outer, compact myocardium of the ventricle is virtually absent (arrow) and the atrium (arrowhead) is severely distended by blood (scale bar $=100 \mu \mathrm{m}$ ). Fig. 4. Transverse section through the cardiac region showing a grossly distended sinus venosus underneath the oesophagus (E) and the relative size of the ventricle (arrow) compared to the grossly dilated and blood-filled atrium (arrowhead) (R: head kidney; H\&E; scale bar = $1 \mathrm{~mm}$ ) 
Other organs (kidney, spleen, liver, muscle, pyloric caecae with pancreatic tissue) showed only mild autolytic changes. This was probably due to sub-optimal fixatation, as whole individuals in formalin were submitted.

Discussion. The severe congestion observed both macroscopically and microscopically, fully confirms that the malformation is lethal and that these fish must have tolerated stress and handling very poorly. Both the aberrant location of the ventricle and the hypoplastic myocardium would, by themselves, account for the severe cardiac failure with congestion. The pathological findings provide no clues regarding the pathophysiological development of this condition, e.g. whether the hypoplastic ventricle led to distension and enlargement of the atrium, or whether the aberrantly located and enlarged atrium actually 'squeezed' the ventricle dorsally. The normal triangular shape of the ventricle is of great importance for optimal cardiac function and output. This rather complex arrangement has evolved to meet the ecophysiological characteristics of the species (Ferguson 1989, Agnisola \& Tota 1994, Sanchez-Quintana et al. 1995). Furthermore, the fact that the ventricle was located on top of the atrium implies further restriction of blood-flow dynamics, as does the almost total lack of myocardial fibre bundles in the compact layer of the ventricle. The complex orientation of these bundles is believed to be of importance in ventricular dynamics and efficiency (SanchezQuintana et al. 1995). That the hearts of these fish were severely compromised is also reflected in the fact that none of them survived the freshwater stage. It has also been reported that fish with other cardiac malformations, e.g. aplasia of the septum transversum (Kaada \& Hopp 1995, Poppe et al. 1998, Poppe \& Nygaard 1999) and hypoplastic ventricle (Poppe \& Taksdal 2000) tolerate handling and other stress factors poorly, probably due to restricted cardiac output in such situations.

All Norwegian rainbow trout originate from a very limited number of specimens, and little new genetic material has been brought into the population. Inbreeding in small breeding populations may cause malformations. Suboptimal conditions, toxic components and many other factors during embryogenesis are also known to cause malformations (Noden \& Lahunta 1985). The hearts of salmonids develop during the egg incubation stage (Gorodilov 1996). High water temperatures during this period have been shown to increase the prevalence of malformations in salmonids (Baeverfjord et al. 1997). Although the

Editorial responsibility: David Bruno,

Aberdeen, Scotland, UK cause(s) of this condition remain unknown, it represents another contribution to the list of cardiac malformations and other husbandry-related diseases of farmed fish in Norway, and it also raises questions about the breeding program (Poppe 2000). All abnormalities and malformations should be registered, analyzed and excluded from the broodfish pool.

Acknowledgements. The authors would like to thank Dr. Bjørn Gjerde for photographic assistance and Suthatip Bolsø for excellent technical work.

\section{LITERATURE CITED}

Agnisola C, Tota B (1994) Structure and function of the fish cardiac ventricle-flexibility and limitations. Cardioscience 5:145-153

Baeverfjord G, Lein I, Åsgård T, Rye M (1997) Shortened operculae in Atlantic salmon (Salmo salar L.) fry reared at high temperatures. In: Abstracts book, European Associaton of Fish Pathologists VIIIth EAFP Conference, 'Diseases of Fish and Shellfish', Edinburgh, p 15

Bruno DW, Poppe TT (1996) A colour atlas of salmonid diseases. Academic Press, London

Ferguson HW (1989) Systemic pathology of fish. Iowa State University Press, Ames

Gorodilov YN (1996) Description of the early ontogeny of the Atlantic salmon, Salmo salar, with a novel system of interval (state) identification. Environ Biol Fish 47:109-127

Kaada I, Hopp P (1995) Laks med deformerte hjerter og misdannede hjertesekker (Atlantic salmon with deformed hearts and abnormal pericardial cavity). Bull Norw Vet Med Assoc 107:773-776

Noden DM, Lahunta A (1985) The embryology of domestic animals. Developmental mechanisms and malformations. William \& Wilkins, Baltimore

Poppe TT (2000) Husbandry diseases in fish farming-an ethical challenge to the veterinary profession. Bull Norw Vet Med Assoc 112:91-96

Poppe TT, Nygaard SMR (1999) Ultrasound imaging as a diagnostic tool in broodfish health control. Bull Norw Vet Med Assoc 111:5-9

Poppe TT, Taksdal T (1997) Cardiac anomalies in farmed Atlantic salmon (Salmo salar L.) In: Abstracts book, European Associaton of Fish Pathologists VIIIth EAFP Conference, 'Diseases of Fish and Shellfish', Edinburgh, p 17

Poppe TT, Taksdal T (2000) Ventricular hypoplasia in farmed Atlantic salmon Salmo salar. Dis Aquat Org 42:35-40

Poppe TT, Midtlyng PJ, Sande RD (1998) Examination of abdominal organs and diagnosis of deficient septum transversum in Atlantic salmon, Salmo salar L., using diagnostic ultrasound imaging. J Fish Dis 21:67-72

Sanchez-Quintana D, Garcia-Martinez V, Climent V, Hurle JM (1995) Morphological analysis of the fish heart ventricle: myocardial and connective tissue architecture in teleost species. Ann Anat 177:267-274

Submitted: December 9, 2001; Accepted: February 5, 2002 Proofs received from author(s): June 21, 2002 